\section{International Scientific Journal Theoretical \& Applied Science}

p-ISSN: 2308-4944 (print) e-ISSN: 2409-0085 (online)

Year: $2016 \quad$ Issue: $12 \quad$ Volume: 44

Published: 09.12.2016 http://T-Science.org

SECTION 7. Mechanics and machine construction.
Natalia Serhiivna Remez

Doctor of technical sciences, professor, Professor at the Department of Environmental Engineering,

IEE "Igor Sikorsky Kyiv Politechnik"

Tetiana Andriivna Osipova

Postgraduate at the Department of Environmental Engineering

IEE NTUU "KPI" osipova_tetiana@ukr.net

Serhii Oleksandrovych Kraichuk

Candidate of technical sciences, Associate Professor at the Department of Economic Cybernetics,

Rivne state university of humanities

Natalia Oleksandrivna Ostapchuk

Candidate of Pedagogic Sciences, Associate Professor at the Department of information and communication technologies and computer science teaching methods,

Rivne state university of humanities

\title{
THE INFLUENCE OF LAYERED FOUNDATION ON THE LANDFILL SETTLEMENT
}

Abstract: The simulation of the settlement of municipal solid waste landfill considering layered soil foundation was held. The landfill describes as a weak soil using a Soft Soil Creep model, soil describes using Mohr-Coulomb model. For the numerical simulation the finite element method was used. The settlement was calculated for landfills, which are based on the loam and clay layers.

Key words: settlement, municipal solid waste, soil foundation, numerical simulation.

Language: Russian

Citation: Remez NS, Osipova TA, Kraichuk SO, Ostapchuk NO (2016) THE INFLUENCE OF LAYERED FOUNDATION ON THE LANDFILL SETTLEMENT. ISJ Theoretical \& Applied Science, 12 (44): 6-11.

Soi: http://s-o-i.org/1.1/TAS-12-44-2 Doi: crossef http://dx.doi.org/10.15863/TAS.2016.12.44.2

\section{ВЛИЯНИЕ СЛОИСТОГО ОСНОВАНИЯ НА ОСАДКУ ПОЛИГОНА ТВЕРДЫХ БЫТОВЫХ ОТХОДОВ}

Аннотация: Проведено моделирование осадки полигонов твердых бытовых отходов с учетом слоистого грунтового основания. Полигон описывается слабым грунтом с использованием модели Soft Soil Сгеер, грунт - моделью Кулона-Мора. Для численного моделирования применяется метод конечных элементов. Осадка рассчитана для полигонов, в основе которых лежат слои суглинка и глины.

Ключевые слова: осадка, твердые бытовые отходы, подстилающий грунт, численное моделирование.

\section{Introduction}

Проблемы состояния окружающей среды приобретают все большую актуальность, в связи с повышением уровня антропогенного воздействия на объекты природы. Серьезной проблемой мирового масштаба выступает увеличение объемов накопления отходов. Так, в Украине ежегодно образуется 52 млн. тонн бытового мусора, количество которого растет ежегодно на $1,5-2,5 \%$. Лишь $5 \%$ отходов перерабатывают, остальные $95 \%$ вывозят на свалки и полигоны. По данным официальной статистики, в Украине действует около 6 тыс. свалок и полигонов мусора общей площадью 7,4 тыс. гектаров, число несанкционированных свалок составляет 32 тыс.[1, с. 85].

Полигоны представляют собой очень сложные системы, в которых множество процессов протекают одновременно. Образования свалочного газа меняет давление газа и жидкости в теле полигона, которое может

ISPC Generalization of scientific results, 
повлиять на пористость, общее напряжение, что вызывает деформации, в первую очередь осадки.

Непредвиденные осадки в конечном счете приводят к ряду проблем, таких как образование трещин в покрывающем слое, повреждения дренажных систем, оползней, приводящих к катастрофическим последствиям, и вызывают разрушение конструкций и даже гибель людей.

Например, в 2010 г. произошел оползень свалки в г. Пайатас (Филипины), в результате чего погибло как минимум 330 человек [2, с.208210].

В связи с постоянным увеличением объемов отходов и, как следствие, увеличение площадей, отводимых под полигоны, а также с интенсивным ростом городов и необходимостью отвода новых земель под строительство, остро встает вопрос об устойчивости полигонов и их возможном использовании в дальнейшем в качестве оснований для инженерных сооружений.

Такая ситуация ставит перед учеными задачу по оценке и прогнозированию устойчивости свалки в качестве основы сооружений.

\section{Materials and Methods}

Анализ литературных источников показал, что экспериментальные методики оценки устойчивости свалки являются затратными и эффективны только для конкретных условий. В свою очередь с помощью лабораторных анализов не удается отобразить условия полигона, в том числе захватить в одном образце все слои и учесть их геотехнические и физико-механические свойства. Поэтому для учета наряженодеформированного состояния слоев полигона и подстилающего грунтового массива и его характеристик целесообразно применять математическое моделирование.

Существующие математические модели, прогнозирующие осадку можно разделить на реологические модели, эмпирические модели, модели, базирующиеся на механике грунтов и модели, учитывающие биодеградацию.

Парк Г.И. и Ли С.Р. предложили модель осадки, учитывающей зависимую от времени биодеградацию отходов с использованием уравнения кинетики первого порядка. Предполагается, что величина осадки выражается через сумму осадок, прямо пропорциональную количеству биоразлагаемых веществ. Однако, определение кинетических коэффициентов или констант гидролиза, а также их изменение в условиях окружающей среды является затруднительным [3, с. 244].

В [4, с. 123-124] Мачадо С.Л. и др.. было отмечено, что необходимо учитывать влияние напряженности, биодеградации отходов и температуры на осадку. Сивакумар Бабу Г.Л. и др. [5, с.1222] разработали составную модель, учитывающую первичную компрессию, механическую ползучесть и биодеградацию, а также проведено исследование влияния этих параметров на осадку твердых бытовых отходов (ТБО) со временем.

Эмпирические модели пытаются имитировать осадку отходов путем корректировки экспериментальных параметров для конкретного участка полигона. В основном используются следующие математические функции: логарифмическая и гиперболическая функция осадки, статическая функция ползучести. [6, с. 140]. Расчет осадки в виде логарифмической функции проводили Йен Б.С. и Сканлон Б.С. в [7, с.477-480].

В [8, с. 373-375] представлено составную реологическую модель, разработанную Маркесом А.С.М и Виларом О.М., для учета первичных и вторичных механизмов сжатия с использованием реологических параметров, которые также учитываются при биодеградации отходов.

Общей чертой этих и других моделей $[9$, c.24-33] является то, что они учитывают только твердые бытовые отходы, их поведение и свойства, пренебрегая такой важной составляющей полигона, как грунты, лежащие в его основе. Именно от типа, прочности, геотехнических свойств подстилающего грунта зависит устойчивость полигона, поскольку наибольшую нагрузку испытывает именно он. Основываясь на наблюдениях крутых склонов свалок, которые остаются стабильными, можно сделать вывод, что основное внимание при анализе устойчивости полигона должно быть уделено материалам, которые лежат в основе ТБО. В настоящее время этот вопрос не изучен.

Для прогнозирования оценки устойчивости полигона предлагается изучение его осадки с обязательным исследованием напряженнодеформированного состояния подстилающего грунтового основания, которое моделируется с учетом поэтапной нагрузки каждого слоя отходами. Это позволит оценить возможность использования полигона в качестве основы здания или конструкции с учетом типа грунта.

Целью работы является прогнозирование оседания полигона ТБО с учетом напряженнодеформированного состояния подстилающих слоистых грунтов, а также при динамических и статических нагрузках для дальнейшего его использования в качестве основы сооружений.

Для прогнозирования осадки закрытого полигона ТБО было проведено математическое моделирование. Покрывающий и подстилающий слои моделировались с помощью модели КулонаМора [10, с.250-252]. При этом тело полигона моделировалось слабым грунтом с учетом ползучести, использовалась модель Soft Soil 


\begin{tabular}{|c|c|c|c|c|c|c|}
\hline Impact Factor: & $\begin{array}{l}\text { ISRA (India) } \\
\text { ISI (Dubai, UAE } \\
\text { GIF (Australia) } \\
\text { JIF }\end{array}$ & $\begin{array}{l}=1.344 \\
=0.829 \\
=0.564 \\
=1.500\end{array}$ & $\begin{array}{l}\text { SIS (USA) } \\
\text { PИНЦ (Russia) } \\
\text { ESJI (KZ) } \\
\text { SJIF (Morocco) }\end{array}$ & $\begin{array}{l}=0.912 \\
=0.234 \\
=1.042 \\
=2.031\end{array}$ & $\begin{array}{l}\text { ICV (Poland) } \\
\text { PIF (India) } \\
\text { IBI (India) }\end{array}$ & $\begin{array}{l}=6.630 \\
=1.940 \\
=4.260\end{array}$ \\
\hline
\end{tabular}

Creep (SSC). В настоящее время данная модель наиболее полно описывает такие свойства слабого грунта, как зависящую от напряжения жесткость, а также вторичную компрессию с учетом ползучести.

Модель имеет следующий вид:

$$
\varepsilon_{v}=\varepsilon_{v}^{e}+\varepsilon_{v{ }_{c}}^{v p}+\varepsilon_{v a c}^{v p},
$$

где $\varepsilon_{v}$ - полная объемная деформация; $\varepsilon_{v}^{e}-$ упругая составляющая деформации; $\varepsilon_{v}^{v p}-$ вязкопластическая составляющая деформации во время консолидации; $\varepsilon_{v}^{v p}{ }_{a c}-$ вязкопластическая составляющая деформации после завершения консолидации. Связь между деформациями выражается в следующем виде:

$$
\begin{gathered}
\varepsilon_{v}^{e}=\kappa^{*} \ln \left(\frac{p^{\prime}}{p_{0}^{\prime}}\right) ; \\
\varepsilon_{v c}^{v p}=\left(\lambda^{*}-\kappa^{*}\right) \ln \left(\frac{p_{p c}^{\prime}}{p_{0}^{\prime}}\right) ; \\
\varepsilon_{v a c}^{v p}=\mu^{*} \ln \left(\frac{\tau_{c}+t^{\prime}}{\tau_{c}}\right),
\end{gathered}
$$

где $\kappa^{*}-$ модифицированный коэффициент набухания; $\lambda^{*}-$ модифицированный коэффициент компрессии (сжатия); $\mu^{*}-$ модифицированный коэффициент ползучести; $t_{c}$ - время окончания первичной консолидации; $t$ время, прошедшее с начала загрузки полигона; $\tau_{c}$ - время консолидации; $p_{0}{ }^{\prime}$ - начальное эффективное напряжение; $p^{\prime}-$ эффективное напряжение; $p_{p c}^{\prime}-$ эффективное предконсолидационное напряжение [11, с. 699701].

Гидродинамические аспекты проблемы состоят в учете фильтрационных сил, действующих на скелет грунтовой среды, и параметров взаимодействия жидкой и твердой фаз грунта (давления, напряжения и пористости) в процессе консолидации. В предположении безвихревого течения фильтрационного потока и распределения сил сопротивления равномерно по сечению элемента используется обобщенный закон Дарси и уравнение неразрывности. Принимается, что сжимаемость скелета и поровой жидкости мала, что приводит к линейной зависимости пористости грунта от давления [12, с. 36].

Полигон, для которого было проведено моделирование, состоит из десяти слоев отходов, толщина каждого слоя 3 м. Угол наклона склона составляет $75^{\circ}$. Осадка определялась с учетом пошагового нагружения полигона спустя 30 лет после его закрытия. Для численного решения задачи использовался метод конечных элементов. Расчетная область покрывалась 256 треугольными элементами.

Было исследовано влияние подстилающего грунта (глина, песок или суглинок) основы на осадку [12, с. 37]. Из анализа численных расчетов следует, что вертикальные деформации полигона с глиной в основе при угле наклона склона $60^{\circ}$ составили 3,8 м. Максимальная вертикальная деформация составила: для полигона с песком 4,34 м, с суглинком - 4,27 м.

Проведено моделирование осадок полигона при слоистых грунтах основания. Рассмотрено три варианта толщины верхнего глинистого слоя: 2 м, 10 м и 15 м. Толщина нижнего суглинистого слоя была постоянной - 10 м.

Деформированная расчетная область полигона с толщиной глинистого слоя основания, равной 2 м представлена на (рис.1). Максимальная вертикальная деформация составила 3,6 м.

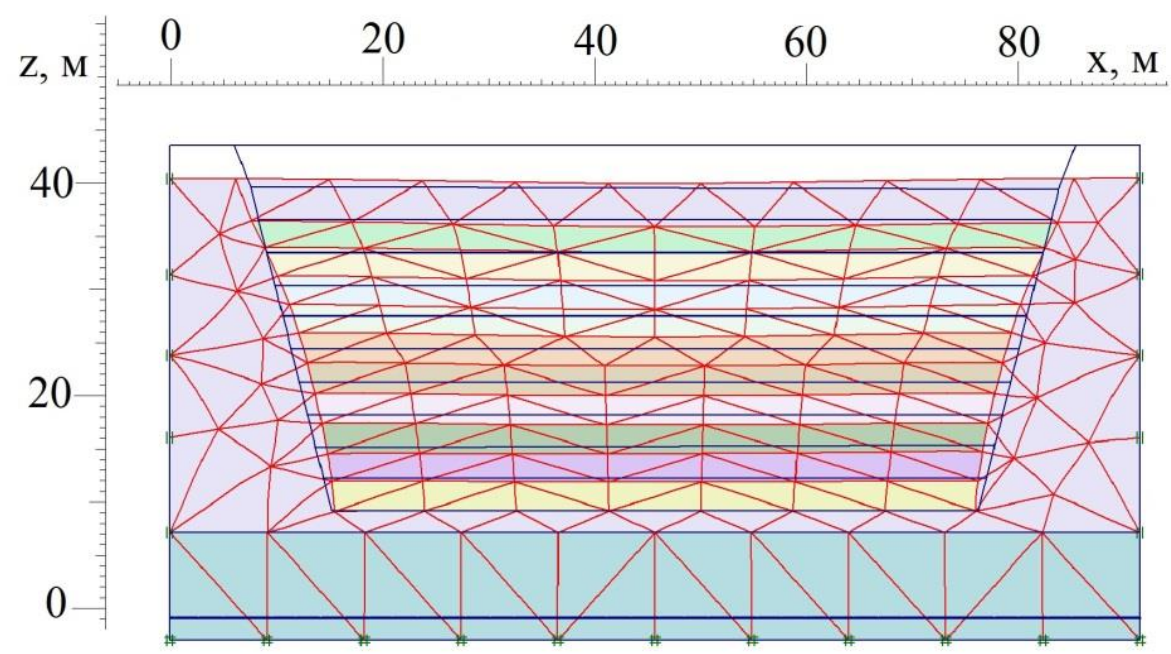

Рисунок 1 - Деформированная расчетная область полигона с толщиной глинистого слоя основания 2 м.

ISPC Generalization of scientific results, 


\begin{tabular}{l|lr|ll|ll} 
& ISRA (India) & $=\mathbf{1 . 3 4 4}$ & SIS (USA) & $=\mathbf{0 . 9 1 2}$ & ICV (Poland) & $=\mathbf{6 . 6 3 0}$ \\
Impact Factor: & ISI (Dubai, UAE) $=\mathbf{0 . 8 2 9}$ & PUHL (Russia) $=\mathbf{0 . 2 3 4}$ & PIF (India) & $=\mathbf{1 . 9 4 0}$ \\
& GIF (Australia) & $=\mathbf{0 . 5 6 4}$ & ESJI (KZ) & $=\mathbf{1 . 0 4 2}$ & IBI (India) & $\mathbf{= 4 . 2 6 0}$
\end{tabular}

Если толщина подстилающего глинистого слоя 10 м, то можно наблюдать, что достигаются меньшие деформации (3,51 м). При увеличении толщины подстилающего глинистого слоя до 15

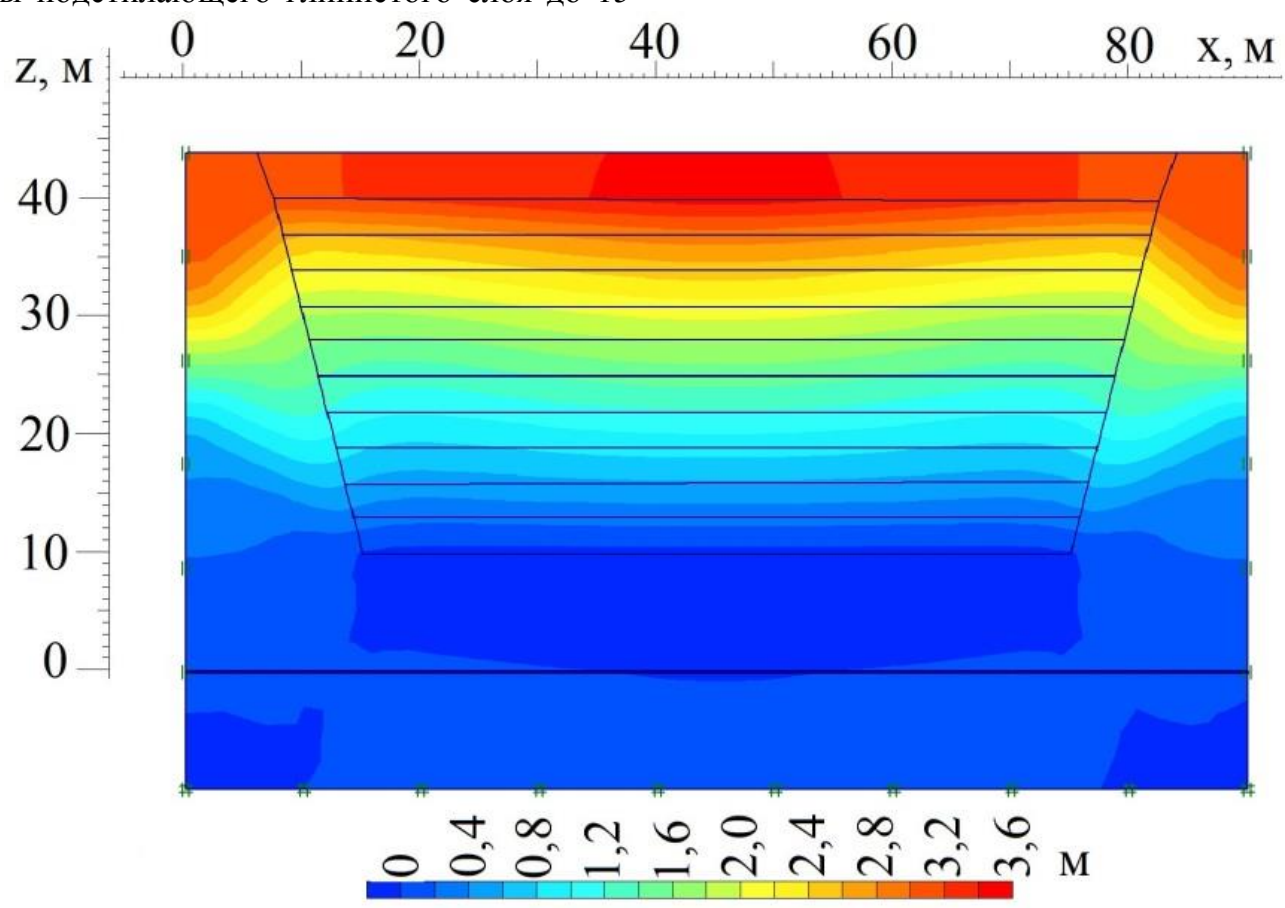

Рисунок 2 - Вертикальные деформации полигона с толщиной глинистого слоя основания 15 м.

Установлено, что если нижний слой глинистый, а верхний суглинистый, то при разной его толщине достигаются практически одинаковые деформации (рис. 3,4 ).

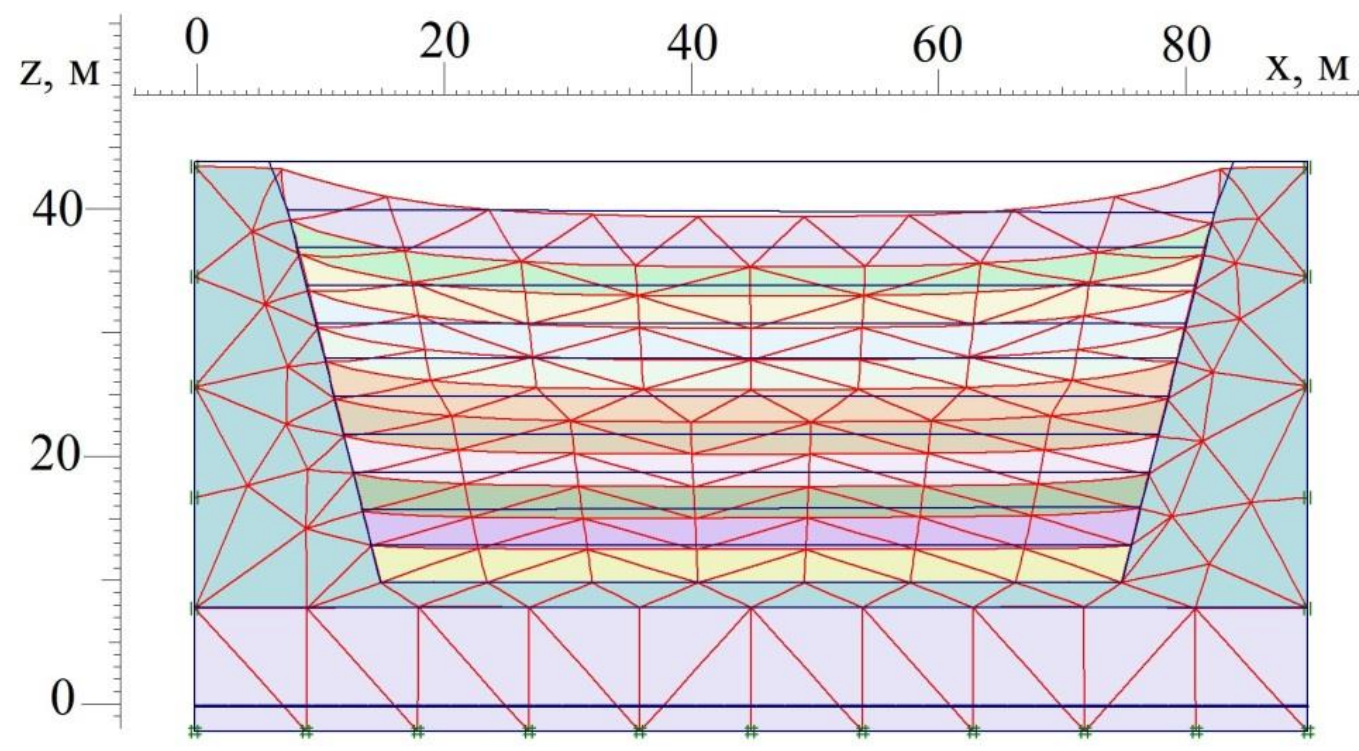

Рисунок 3 - Деформированная расчетная область полигона с толщиной суглинистого слоя основания 2 м. м достигаются наименьшие деформации (3,48 м), по сравнению с двумя предыдущими вариантами (рис.2).
ISPC Generalization of scientific results, Scranton, USA 


\begin{tabular}{l|lrl|l|ll} 
& ISRA (India) & $=\mathbf{1 . 3 4 4}$ & SIS (USA) & $=\mathbf{0 . 9 1 2}$ & ICV (Poland) & $=\mathbf{6 . 6 3 0}$ \\
Impact Factor: & ISI (Dubai, UAE) $=\mathbf{0 . 8 2 9}$ & PVHU (Russia) $=\mathbf{0 . 2 3 4}$ & PIF (India) & $=\mathbf{1 . 9 4 0}$ \\
& GIF (Australia) & $\mathbf{0 . 5 6 4}$ & ESJI (KZ) & $=\mathbf{1 . 0 4 2}$ & IBI (India) & $\mathbf{4 . 2 6 0}$
\end{tabular}

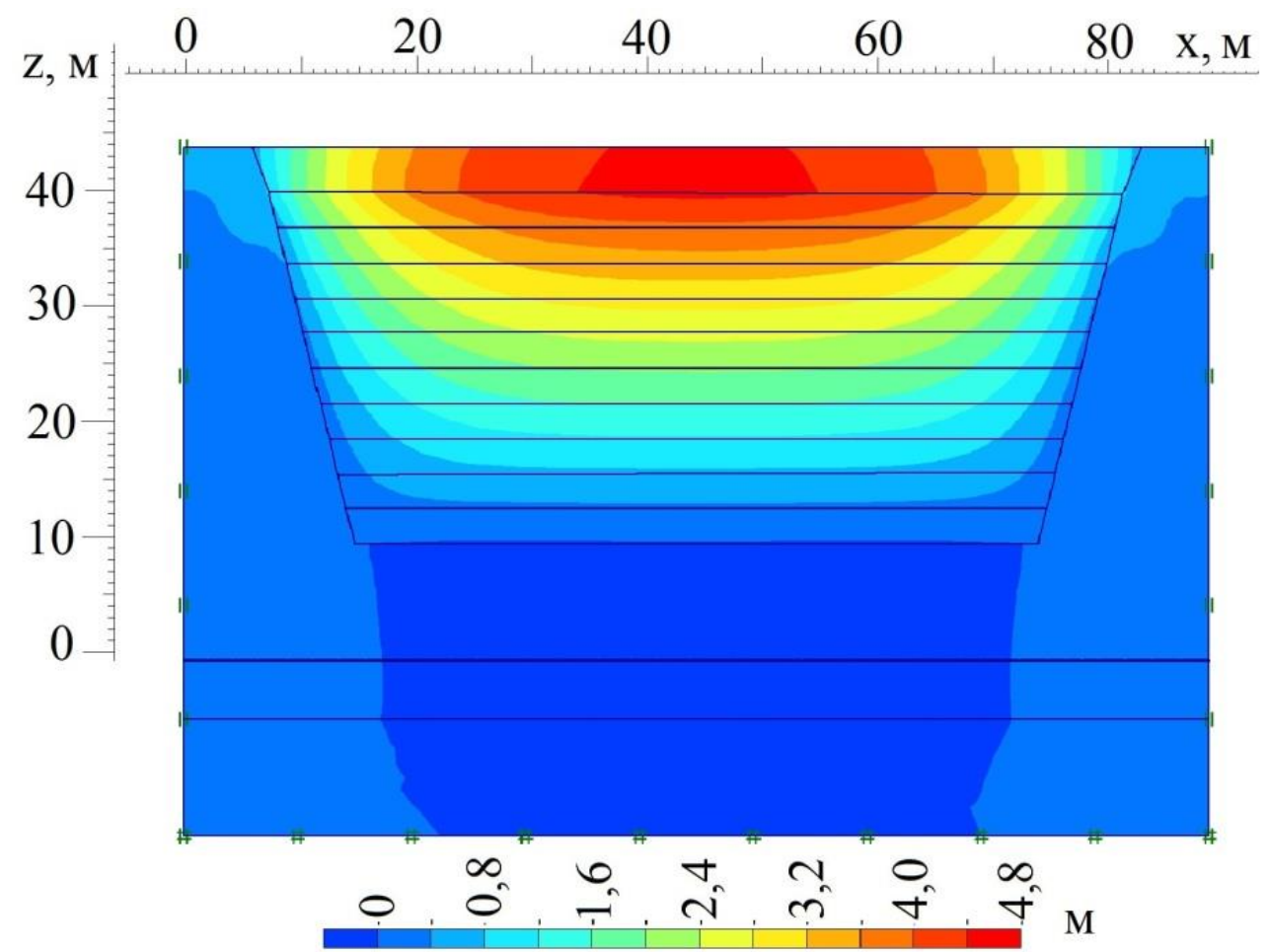

Рисунок 4 - Вертикальные деформации полигона с толщиной суглинистого слоя основания 15 м.

При этом величина деформации 4,49 м, что значительно больше, чем когда нижний подстилающий слой суглинистый. Это можно объяснить тем, что суглинистый грунт менее плотный и более сжимаемый и на него оказывает давление тело полигона, а нижний более плотный глинистый грунт действует как твердая стенка.

\section{Выводы:}

1. Разработано пространственную математическую модель процесса консолидации тела полигона ТБО, в которой впервые предложено учитывать подстилающий грунт, так как он является одним из основных факторов при формировании осадки.

2. Разработана эффективная методика расчета напряженно-деформированного состояния полигона и подстилающего и покрывающего грунтов с использованием современных моделей: Кулона-Мора для слоев грунта и SSC для отходов.

3. Впервые установлено, что при одинаковых параметрах полигона подстилающий грунтовый слой оказывает значительное влияние на величину осадки: чем более плотный и менее пористый грунт, тем меньше осадка. В частности, если грунтовая основа представлена глиной, то достигается осадка на $23 \%$ меньше, чем с песком, и на $14 \%$ меньше, чем с суглинком.

4. При исследовании зависимости влияния слоистого грунта на его осадку установлено, если первый подстилающий слой глинистый, то достигается осадка на 19,8-22,5\% меньше, чем когда первый слой суглинок в зависимости от толщины первого слоя. Причем если первый слой суглинистые, то его толщина существенно не влияет на величину осадки.

\section{References:}

1. Tykhenko VS (2014) Realizatsiia natsionalnyh ta nadnatsionalnyh proektiv zbyrannia ta pererobky pobytovyh vidhodiv $\mathrm{v}$ Ukraini. Vistnyk Dnipropetrovskogo universytetu, seriia ekonomika, vol. 22. № 10/1, 8 (2), 84-88.
2. Navid H. Jafari, Stark TD, Merry SM (2013) The July 102000 Payatas Landfill Slope Failure. International Journal of Geoengineering Case Histories, vol. 2, № 3, 208-228.

ISPC Generalization of scientific results, 


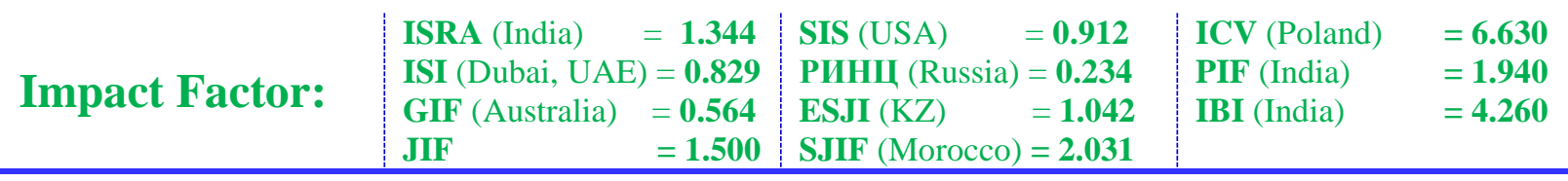

3. Park HI, Lee SR (1997) Analysis of Long-Term Settlement of Municipal Solid Waste Landfills as Determined by Various Settlement Estimation Methods. Journal of the Air \& Waste Management Association, (57), 243251.

4. Machado SL, Carvalho MF, Vilar OM (2009) Modeling the influence of biodegradation on sanitary landfill settlements. Soils and Rocks, Sao Paulo 32 (3), 123-134.

5. Sivakumar Babu GL, Reddy KR, Chouskey SK (2011) Parametric Study of MSW Landfill Settlement Model. Waste Management, vol. 31, no. 6, 1222-1231.

6. Sivakumar Babu GL, Reddy KR, Chouskey SK, Kulkarni HS (2010) Prediction of Long-term Municipal Solid Waste Landfill Settlement Using Constitutive Model. Practice Periodical of Hazardous, Toxic and Radioactive Waste Management. New York, ASCE, 2010, vol. 14, no. 2, 139-150. DOI: http://dx.doi.org/10.1061/(ASCE)HZ.19448376.0000024.

7. Yen BC, Scanlon BS (1975) Sanitary landfill settlement rates. J. Geotech. Eng., 101(5), 475487.
8. Marques ACM, Vilar OM (2003) Composite comopressibility model for municipal solide waste. J. Geotech. Geoenviron. eng., 129(4), 372-378.

9. Behnam Fatahi (2013) Improving Geotechnical Properties of Closed Landfills for Redevelopment Using Fly Ash and Quicklime, University of Technology, Sydney. Faculty of Engineering and Information Technology, 544 $\mathrm{p}$.

10. Vermeer PA, Neher HP (1999) A Soft Soil Model that Accounts for Creep. Proc. Int. Symp. "Beyond 2000 in Computational Geotechnics", Amsterdam, Balkema, Rotterdam, 249-261.

11. Rangeard D, Zentar R, Abriak NE (2004) Influence of soil model on the analysis of pressuremeter test. In proceedings of Int. Conf. on Numer. Models in Geomech., NUMOG IX, 699-705.

12. Remez NS, Osipova TA (2015) Prognozirovanie ispolzovaniia poligonov TBO $\mathrm{v}$ kachestve osnovaniia sooruzheniia. ISJ Theoretical \& Applied Science 7 (27), 34-39. 